\title{
Pulsatilla Extract
}

National Cancer Institute

\section{Source}

National Cancer Institute. Pulsatilla Extract. NCI Thesaurus. Code C71828.

An herbal remedy derived from perennial plants of the genus Pulsatilla, a native to central and northern Europe and southern England. The plant contains lactones, saponins, anemone camphor, tannins, and a volatile oil. This remedy has been used traditionally to induce abortions and childbirth. 